\title{
Ellis Van Creveld syndrome
}

INSERM

\section{Source}

INSERM. (1999). Orphanet: an online rare disease and orphan drug data base. Ellis Van

Creveld syndrome. ORPHA:289

Ellis-van Creveld syndrome (EVC) is a skeletal and ectoderlam dysplasia characterized by a tetrad of short stature, postaxial polydactyly, ectodermal dysplasia, and congenital heart defects. 